\title{
The Relationship Between Maternal Incarceration and Foster Care Placement
}

\author{
Amy Dworsky*, Allen Harden and Robert Goerge \\ Chapin Hall at the University of Chicago, 1313 E. $60^{\text {th }}$ St., IL 60637-2830, USA
}

\begin{abstract}
We use administrative data to examine the temporal relationship between maternal incarceration and foster care placement among incarcerated mothers and their children in Cook County, Illinois. We also compare the discharge outcomes of foster children whose mothers were incarcerated to the discharge outcomes of all foster children in Illinois. We found that more than three quarters of the children who entered foster care did so prior to the mother's first observed incarceration and that children whose mothers had been incarcerated were more likely to be adopted and less likely to be reunified than foster children generally. The implications of these findings for both the child welfare and criminal justice systems are discussed.
\end{abstract}

Keywords: Maternal incarceration, foster care, adoption and safe families act.

\section{INTRODUCTION}

According to the Bureau of Justice Statistics, an estimated 1.7 million minor children, or approximately 2.3 percent of the total U.S. child population, had a parent in federal or state prison in 2007. This reflects a 79 percent increase in the number of children with an incarcerated parent since 1991 [1]. Although prison populations are still overwhelmingly male, the female prison population has been growing at a much faster rate. Consequently, the number of mothers in state or federal prisons increased 122 percent between 1991 and 2007 compared with a 76 percent increase in the number of fathers [1].

Much of this increase has been driven by the "war on drugs." Although women tend to play more peripheral roles in the drug trade than men, women are often subjected to harsh mandatory minimum sentences because of drug laws that have expanded criminal liability. In fact, women are more likely to be serving time for drug-related offenses than men $[2,3]$.

As the number of incarcerated mothers has increased, so too has the number of children whose mother is incarcerated. The number of children with a mother in prison increased 133 percent between 1991 and 2007. By comparison, there was a 77 percent increase in the number of children with a father in prison [1]. This means that although children are still far more likely to have a father than a mother in prison, they are much more likely to have an incarcerated mother than ever before.

The impact of parental incarceration on children's living arrangements varies depending on whether the incarcerated parent had been the primary, if not sole, caregiver [4]. This, in turn, is often a function of gender. Incarcerated mothers are more likely to have been living with their children, and

*Address correspondence to this author at the Chapin Hall at the University of Chicago, 1313 E. $60^{\text {th }}$ St., IL 60637-2830, USA; Tel: 773-256-5164; Fax: 773-256-5364; E-mail: adworsky@chapinhall.org much more likely to be their children's sole custodial parent, than incarcerated fathers. For example, 61 percent of the mothers in a nationally representative sample of state prisoners reported that they had been living with their children prior to incarceration compared with only 42 percent of fathers. Moreover, 77 percent of the mothers who had been living with their children identified themselves as having been the primary caregiver as compared with only 26 percent of the fathers who had been living with their children [1].

One consequence of this gender difference in preincarceration care giving responsibilities is that children whose mother is incarcerated are far more likely to be cared for by someone besides their other parent than children whose father is incarcerated. Approximately 63 percent of mothers in that nationally representative state prison sample compared with only 12 percent of fathers reported that their children were not being cared for by their other parent [1].

In most cases, the non-parental caregiver is the children's grandparent or another relative. Approximately 45 percent of the mothers compared with only 13 percent of the fathers in that nationally representative sample of state prisoners reported that a grandparent was currently caring for their children [1]. In other cases, however, it is the state that plays that role. Approximately 11 percent of the mothers but only 2 percent of the fathers in that nationally representative sample of state prisoners reported having children in a foster home or institution [1].

As long as the rate of maternal incarceration continues to increase, so too will the number of foster children who have a mother in jail or prison. Unfortunately, not much is known about the relationship between foster care placement and maternal incarceration. For example, we lack basic information about the number of foster children whose mother is incarcerated, the likelihood that foster care placement will precede rather than follow maternal incarceration, the effect of having an incarcerated mother on the number or type of placements children experience while 
they are in care, their length of stay, or their permanency outcomes (e.g., reunification versus adoption). Answering these questions is important if child welfare agencies are to develop practices or policies that counteract any negative effects that having an incarcerated mother might have on children's permanency outcomes or their experiences while in foster care

A number of factors have contributed to our lack of knowledge about the relationship between maternal incarceration and foster care placement. In some cases, information that mothers are in jail or prison may not be available because they are reluctant to make the child welfare agency aware of their incarceration. In others, information about maternal incarceration may not be available because it was not the reason children entered foster care.

These problems notwithstanding, researchers are beginning to explore the relationship between foster care placement and maternal incarceration. Researchers from the Vera Institute of Justice used data from New York City's Administration for Children's Services and New York State's Division of Criminal Justice Services to examine criminal justice involvement among the biological mothers of foster children who entered care in $1991(\mathrm{n}=7,657)$ or $1996(\mathrm{n}=7,128)[5]$.

Approximately 22 percent of the mothers in both cohorts had ever been incarcerated during their adult lives, and mothers in both cohorts where somewhat more likely to be sentenced to jail or prison after rather than before their children's foster care entry. Only half of the ever incarcerated mothers spent time in jail or prison while their children were in foster care, and they were most likely to have been sentenced during the first year after their children had been placed. By contrast, when the mother's incarceration and the children's foster care placement did not overlap, the temporal relationship varied by cohort. Mothers in the 1991 cohort were about as likely to have been sentenced to jail or prison in the year before as in the year after their children had entered foster care whereas mothers in the 1996 cohort were much more likely to be have sentenced within the year before.

Researchers from the Vera Institute of Justice also used data from those same two sources to examine criminal justice involvement among the biological mothers of children who first entered foster care in FY 1997 [6]. Just over five percent of the mothers were incarcerated for at least 30 consecutive days during their children's first three years in foster care. Consistent with the results of the earlier study, 90 percent of the maternal incarcerations that overlapped with a foster care placement began after the children had been placed in foster care as did 85 percent of the arrests that led to those incarcerations. Moreover, in a majority of the cases where maternal incarceration and foster care placement overlapped, the mother had been convicted of drug sales or possession.

In addition to examining the temporal relationship between maternal incarceration and foster care placement, researchers from the Vera Institute have compared the discharge outcomes of children whose mother had been incarcerated with the discharge outcomes of children whose mother had not. Compared with children whose mothers were never incarcerated, children whose mothers had been incarcerated for at least two years were more likely to be adopted and less likely to be reunified, even after controlling for maternal and child age [5].

The primary purpose of this research was to determine whether the results of the two Vera Institute studies would generalize to a different major urban area. Replicating the results would be important because the child welfare and criminal justice systems in one jurisdiction can differ in significant ways from the child welfare and criminal justice systems in another jurisdiction. With this aim in mind, we undertook a similar study of the relationship between maternal incarceration and foster care placement $\mathrm{n}$ Cook County (Chicago), Illinois. ${ }^{1}$

\section{METHOD}

We used adult admission and exit files from the Illinois Department of Corrections and the Cook County Jail to identify female offenders from Cook County who were incarcerated in state prison or Cook County jail between January 1993 and June 2001. This time frame was period for which corrections data were available while the research was being conducted.

We identified a total of 52,883 female offenders. Approximately 80 percent of these female offenders $(\mathrm{n}=$ $42,246)$ reported being mothers. These mothers reported a total of 124,626 children, which corresponds to a mean of 2.95 children per mother. Because the administrative records contained no information about the children's age or date of birth, we do not know if they were still minors. Nor do we know if the mother had been their primary caregiver prior to her incarceration.

We linked the corrections records for the female offenders who reported being mothers to public assistance (i.e., AFDC/TANF, food stamp and Medicaid) data from the Illinois Department of Human Services (IDHS) and to child welfare services data from the Illinois Department of Children and Family Services (IDCFS). The IDHS data covered the period July 1989 through June 2001. The DCFS data included records for (1) all Child Protective Services (CPS) investigations between October 1993 and June 2001, (2) all founded CPS investigations between April 1987 and June 2001, and (3) all foster care placements between January 1977 and June 2001. The CPS investigations data came from the Child Abuse and Neglect Tracking System (CANTS) and the placement data care from the Child and Youth Centered Information System (CYCIS).

The data were linked using a technique known as probabilistic matching. Multiple pieces of identifying information such as name, birth date, gender, and race/ethnicity are used to calculate the probability that two records from different databases belong to the same individual [7]. We found records for 26,669 or 63 percent of the self-reported mothers and a total of 86,313 or 69 percent

\footnotetext{
${ }^{1}$ These analyses were part of a much larger project, the Women in Prison study, that was led by Drs. Robert LaLonde and Susan George. Both were researchers at the University of Chicago's Harris School of Public Policy. That research was funded by the Chicago Community Trust and the George Soros Foundation.
} 


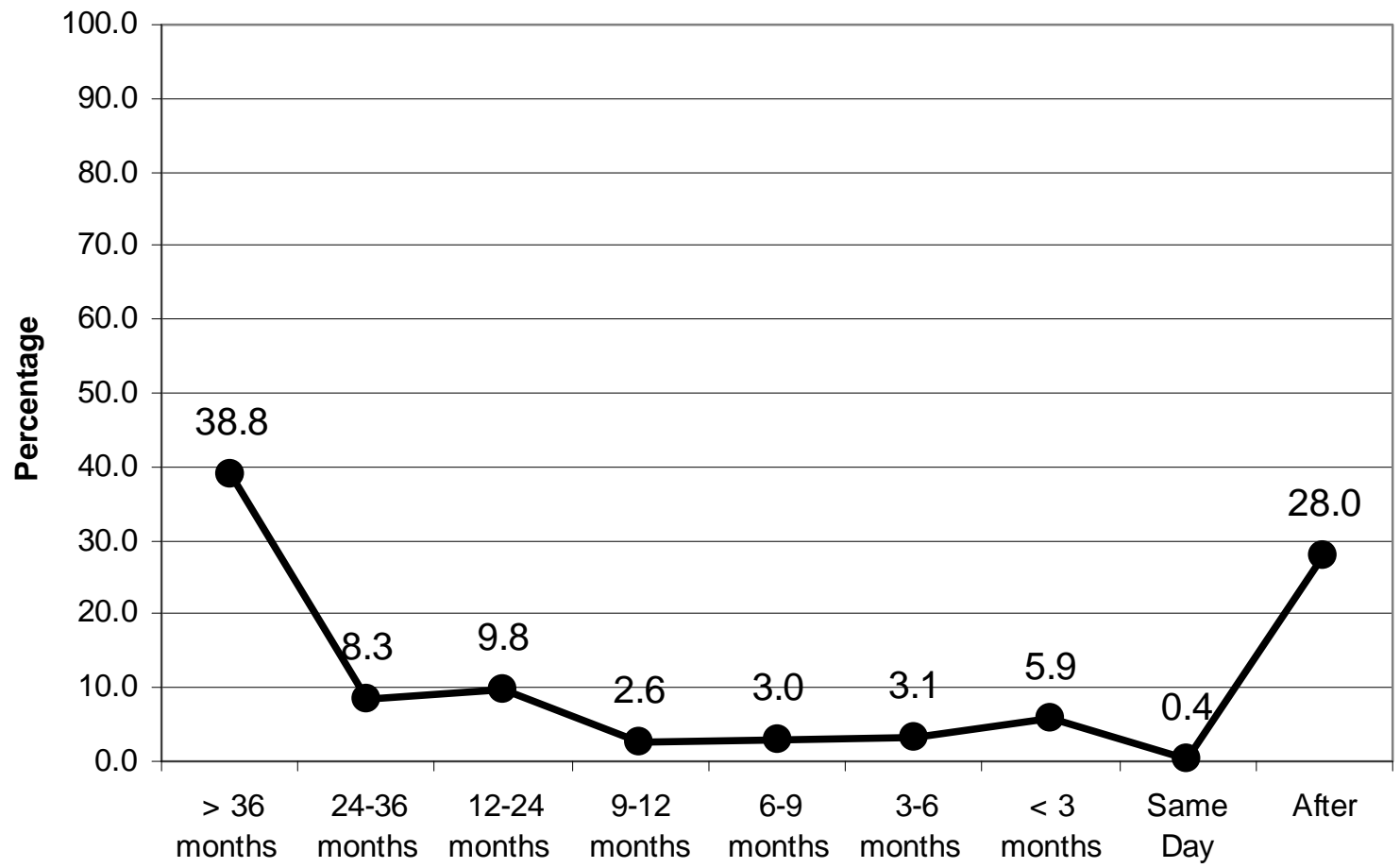

Fig. (1). Timing of first entry into foster care relative to start of mother's first observed interaction.

of their self-reported children. This corresponds to a mean of 3.24 children per mother.

Before turning to our results, we want to acknowledge the major limitations of our study. First, because we used probabilistic matching to link records across databases, some both false positives (i.e., deciding that two records belong to the same individual when, in fact, they don't) and false negatives (i.e., deciding that two records do not belong to the same individual when, in fact, they do) may have occurred.

Second, we were only able to identify incarcerated mothers and their children who had received benefits from the Illinois Department of Human Services or had some type of involvement with the Illinois Department of Children and Family Services. Although the IDHS and IDCFS data allowed us to capture 63 percent of the self-reported mothers and 69 percent of their self-reported children, we did not find any records for a significant percentage of both groups. Moreover, the incarcerated mothers and children for whom we did find records do not comprise a random sample. Rather, they are those who had had some involvement with the child welfare system or who had received public assistance benefits.

One consequence of using this approach to identify our sample is that children who had ever been placed in foster care are likely to be over-represented. Indeed, as we report below, a high percentage of the incarcerated mothers had a child with a history of foster care placement. This sample may have led us to overestimate the prevalence of foster care placement among the children of incarcerated mothers. It also means that the rate of child welfare services involvement among the mothers and children for whom we were unable to find records is probably much lower than the rate of child welfare services involvement among those for whom records were found.
And third, we did not look at the relationship between foster care placement and paternal incarceration. In part, this reflects the fact that incarcerated mothers are much more likely than incarcerated fathers to have been the custodial parents of their children [1].

\section{RESULTS}

\section{Foster Care Placement}

We looked at foster care placement first at the level of the incarcerated mothers and then at the level of their children. Twenty-seven percent of the incarcerated mothers $(\mathrm{n}=7,281)$ were the parent of a child who had ever been placed in foster care. Altogether, the children of these incarcerated mothers experienced a total of 26,323 foster care spells, or a mean of 1.22 spells per child. Seventy-four percent of those spells began before their mother's first observed incarceration. ${ }^{2}$

Twenty five percent of the children whose mother had ever been incarcerated had ever been placed in foster care ( $\mathrm{n}$ $=21,533)$. Seventy-two percent of these ever-placed children had entered foster care prior to the start of their mother's first observed incarceration $(\mathrm{n}=15,514)$, including 39 percent who been placed three or more years before $(\mathrm{n}=$ $8,364)$.

\section{Discharge Outcomes}

Looking only at first foster care placements, we compared the discharge outcomes of the children whose mother had ever been incarcerated to the discharge outcomes of all children in DCFS care. Children whose mother had ever been incarcerated were less likely to have been

\footnotetext{
${ }^{2}$ We refer to first observed incarceration because it is possible that some of the mothers had been incarcerated prior to 1993, the first year for which we had IDOC records.
} 
reunified (25.0 percent) and more likely to have been adopted (34.2 percent) than foster children in Illinois generally (39.7 and 27.3 percent, respectively). Children whose mother had ever been incarcerated were also much more likely to still be in foster care when the observation period ended on June 30, 2001 (23.3 percent) than the general population of Illinois foster children ( 5.5 percent). All of these differences were statistically significant.

\section{DISCUSSION AND CONCLUSIONS}

One important finding to emerge from this research concerns the temporal relationship between maternal incarceration and foster care placement. Although some children probably entered foster care as a result of their mother being incarcerated, more than three quarters of the children who had ever been in foster care had first been placed prior to the first observed incarceration of their mother. This is consistent with what the Vera Institute researchers found when maternal incarceration and foster care placement overlapped. Importantly, our results were similar despite differences in jurisdictions and the sampling strategies that were used. We began with a sample of incarcerated mothers and determined which of their children had been placed in foster care, whereas they began with a sample of foster children and determined which of their mothers had spent time in jail or prison.

The fact children were often placed in foster long before their mother's first observed incarceration can be interpreted in several ways. One possibility is that the mother had been engaged in unlawful activities at the time her children were removed from home but that the child welfare system responded to the mother's parenting problems before the criminal justice system responded to her illegal behavior. This might be the case particularly when mothers are incarcerated for the sale or possession of drugs. Alternatively, the placement of children in foster care may have precipitated a downward spiral or cause a downward spiral that had already begun to accelerate. Additional research is needed to determine whether either or both of these scenarios is correct.

Our other major finding is that foster children whose mothers are incarcerated tend to experience different discharge outcomes than the general population of children in foster care. Specifically, they are less likely to be reunified and more likely to be adopted. Again, this is consistent with what the Vera Institute researchers reported [5].

Several factors may have contributed to this result. First, reunification becomes much more complicated when a mother is incarcerated. Assuming that the child welfare agency is aware of a mother's incarceration and is kept apprised of the correctional facility she is in, which is not always the case, the parent-child relationship must be maintained through regular visits and other contacts for reunification to remain a viable option $[8,15]$. However, arranging and supervising visits with incarcerated parents requires time, resources and cooperation between the child welfare agency and correctional facility, and children must be prepared for what they will experience. It is also more difficult to engage incarcerated mothers in the services they need to improve their parenting [9].
Second, to prevent the long-term placement of children in foster care, the Adoption and Safe Families Act (AFSA) of 1997 requires child welfare agencies to file a petition to terminate parental rights (TPR) if a child has been in foster care for 15 of the most recent 22 months or determined by a court to be an abandoned infant, although exceptions can be made if a child is in the care of relatives, if doing so would not be in a child's best interest or if family reunification services have not been provided. The " $15 / 22$ months" provision is of particular relevance to mothers incarcerated in either state or federal prisons, who often serve sentences of two years or more ${ }^{3}[10]$.

Because our study included mothers who had been incarcerated not only in state prison but also in Cook County jail, only four percent of their first observed incarcerations lasted 15 months or more. Had we limited our analysis to the 1,938 mothers who served time in state prison during their first observed incarceration, the " 15 of 22 " months provision would have applied to as many as 37 percent.

Not much is know about the number of incarcerated parents whose parental rights have been terminated as a result of this provision [11]. One study found a 250 percent increase in the number of TPRs involving incarcerated parents during the 5 years after ASFA became law compared with a 30 percent increase during the 5 years before [12]. Another found that incarceration played a role in 18 percent of the cases in which parental rights were terminated [13].

Many states include parental incarceration as a factor that must be taken into account when courts make decisions about the termination of parental rights, and in some states sentence length is a determining factor. Parental incarceration can also qualify as an "aggravated circumstance," relieving child welfare agencies from the need to make "reasonable efforts" to reunify families or limiting the number of months in which "reasonable efforts" must be made. At the same time, statutes in six states, including Nebraska and New Mexico, expressly prohibit filing for a termination of parental rights due to incarceration per se. Indeed, Colorado allows for an exception to the " $15 / 22$ months" TPR filing requirement when a parent is incarcerated $[13,14]$.

These results have implications for both the child welfare and criminal justice systems.

To the extent that the process of family reunification is much more complicated when mothers are in jail or prison, child welfare agencies would appear to have an interest in preventing the incarceration of mothers whose children are in foster care, or at least reducing the length of their incarceration. Because the risk of maternal incarceration is likely to be particularly high among mothers who have a history of criminal justice system involvement, even if only for minor offenses, these mothers should be targeted for services, such as drug abuse treatment, that may prevent them from becoming trapped in the downward spiral that too often seems to lead to maternal incarceration.

\footnotetext{
${ }^{3}$ According to the 1997 Surveys of Inmates in State and Federal Correctional Facilities, 63 percent of mothers incarcerated in state prison and 74 percent of mothers incarcerated in federal prison expected to serve at least two years.
} 
In addition, the fact that children whose mothers are incarcerated are more likely to be adopted and less likely to be reunified with their family than foster children in general raises questions about efforts to achieve reunification when mothers are in prison or jail. Although there will cases in which adoption rather than reunification is in a child's best interest, AFSA does include a "best interest of the child" exception to " $15 / 22$ months" rule. Better coordination between child welfare agencies and correctional facilities is especially critical because frequency of visitation is one of the criteria that may be used in deciding whether an exception to the " $15 / 22$ months" rule should be made [11]. The two systems must work together to facilitate rather than create barriers to regular visits between foster children and their incarcerated mothers [11, 15]. Moreover, when decisions are made as to where a mother will be incarcerated, the fact that her children are in foster care should be taken into account.

Although these findings contribute to our knowledge about the relationship between maternal incarceration and foster care placement, a number of important questions have yet to be addressed. First, how does maternal incarceration affect children's experiences in foster care (e.g., length of stay, frequency of placement changes, and type of care in which they are placed)? Second, how do both the short- and long-term outcomes of foster children whose mothers are incarcerated compare to those of foster children whose mothers are not incarcerated or to those of children whose mothers who are incarcerated but who are not in foster care? Third, how does the relationship between maternal incarceration and foster care placement vary depending on the types of offenses for which mothers have been incarcerated or the strictness of state mandatory sentencing guidelines? Finally, is the greater likelihood of adoption and lower likelihood of reunification among foster children whose mothers are incarcerated a function of their incarceration per se or can it be explained by maternal characteristics associated with incarceration? Some of these questions could be addressed with administrative data similar to the data that we used; others would require additional data.

\section{ACKNOWLEDGEMENT}

None declared.

\section{CONFLICT OF INTEREST}

None declared.

\section{REFERENCES}

[1] Glaze L, Maruschak L. Parents in prison and their minor children. Washington, DC: U.S. Department of Justice, Bureau of Justice Statistics 2008 .

[2] Mauer M, Potler C, Wolf R. Gender and justice: women, drugs, and sentencing policy. Washington, DC: The Sentencing Project 1999.

[3] Lapidus L, Luthra N, Verma A, Small D, Allard P, Levingston K Caught in the net: the impact of drug policies on women and families. Washington, DC: American Civil Liberties Union 2005.

[4] Travis, J, McBride E, Solomon A. Families left behind: The hidden costs of incarceration and reentry. Washington, DC: Urban Institute 2005

[5] Ehrensaft M, Khashu A, Ross T, Wamsley M. Patterns of criminal conviction and incarceration among mothers of children in foster care in New York City. New York: Vera Institute of Justice and Administration for Children's Services 2003.

[6] Ross T, Khashu A, Wamsley M. Hard data on hard times: An empirical analysis of maternal incarceration, foster care, and visitation. New York, NY: Vera Institute of Justice 2004.

[7] Goerge R, Lee BJ. Matching and cleaning administrative data. In: Ver Ploeg M, Moffit A, Citro C, Eds. Studies of welfare populations: Data collection and research issues. Washington, DC: National Academy Press 2002, pp.197-219.

[8] LaVigne N, Davies E, Brazzell D. Broken bonds: Understanding and addressing the needs of children with incarcerated parents. Washington, DC: Urban Institute 2008.

[9] Nickel J, Garland C, Kane L. Children of incarcerated parents: an action plan for federal policymakers. New York: Council of State Governments Justice Center 2009.

[10] Mumola C. Incarcerated parents and their children (NCJ-182335). Washington, DC: U.S. Department of Justice, Bureau of Justice Statistics 2000 .

[11] Christian S. Children of incarcerated parents. Washington, DC: National Conference of State Legislatures 2009.

[12] Genty P. Damage to family relationships as a collateral consequence of parental incarceration. Fordham Urban Law Journal 2002-2003; 30: 1671-84.

[13] Zavez M. Use of the Adoption and Safe Families Act at15/22 months for incarcerated parents. Vermont Law Rev 2008; 33(2): 187-200.

[14] Lee A, Genty P, Laver M. The impact of the Adoption and Safe Families Act on the children of incarcerated parents. Washington, DC: Child Welfare League of America 2005.

[15] Notkin S, Weber K, Golden O, Macomber J. Intentions and results: A look back at the Adoption and Safe Families Act. Washington, DC: Center for the Study of Social Policy and the Urban Institute 2009. 